\title{
OS DIREITOS FUNDAMENTAIS E OS FUNDAMENTOS DA DIFERENÇA
}

\section{REVISÃo BIBLIOMÉTRICA}

ROMUALDO, Diego Paulo de Oliveira ${ }^{1}$

SENA, Letícia Domingos ${ }^{2}$

ROMUALDO, Diego Paulo de Oliveira. SENA, Letícia Domingos. Os direitos fundamentais e os fundamentos da diferença. Revista Científica Multidisciplinar Núcleo do Conhecimento. Ano 05, Ed. 01, Vol. 03, pp. 67-75. Janeiro de 2020. ISSN: 2448-0959, Link de acesso: https://www.nucleodoconhecimento.com.br/educacao/fundamentos-dadiferenca

\section{RESUMO}

Este estudo apresenta uma a revisão bibliográfica dos conceitos que fundamentam a filosofia da diferença a partir da ótica de Jacques Derrida, contemplando nessa perspectiva os fundamentos dos direitos humanos fundamentais. Apresenta os conceitos linguísticos de "signo", "significado" e "significante" tal como descritos por Ferdinand de Saussure na semiologia clássica. Apresenta, também, a forma como

\footnotetext{
${ }^{1}$ Mestrando em Educação pela Faculdade de Educação da UFMG; Especialização em Metodologia de Ensino de História e Geografia pela Faculdade Internacional de Curitiba; Graduado em Ciências Militares - Ênfase em Defesa Social pela Academia da Polícia Militar de Minas Gerais; Graduando em Teologia Interconfessional pelo Centro Universitário Internacional Uninter.

2 Mestranda em Educação pela Faculdade de Educação ( $\mathrm{FaE})$ da Universidade Federal de Minas Gerais, Investigadora da Polícia Civil de Minas Gerais, Especialista em Coordenação Pedagógica pela Universidade Federal de Ouro Preto e graduada em Pedagogia pela Universidade Vale do Rio Doce.
} 
Jacques Derrida se apropria desses conceitos e os expande em suas obras, fazendo da "diffèrance" o fundamento da identidade. Como conclusão, temos a explanação entre os conceitos mencionados e a garantia dos direitos fundamentais, que devem ser assegurados a todos os seres humanos, não obstante de qualquer diferença que os singularize ou segregue.

Palavras-chave: Signo, diferença, identidade, Direitos fundamentais.

\section{INTRODUÇÃO}

No campo do Direito Internacional, existe uma gama de direitos que cabem a qualquer pessoa: tratam-se dos chamados direitos fundamentais, denominados assim porque têm por base a dignidade de cada pessoa. Considerando-se o fato de serem seres humanos (KANT, 2007) segue-se que todas as pessoas são sujeitos a quem devem ser garantidos os tais direitos.

Ao refletir sobre a questão dos Direitos Humanos e analisar a letra das leis, declarações e pactos criados nos últimos setenta anos, percebe-se o claro desejo da comunidade internacional em garantir o acesso aos direitos mais básicos a todas as pessoas. A Declaração Universal dos Direitos Humanos (ONU, 2009) acha-se cravada de locuções e discursos que têm como pretensão não permitir a exclusão de nenhuma pessoa. Nesse sentido, pode-se depreender que nem todas as pessoas, até o advento da declaração, eram consideradas sujeitos a quem se destinavam os direitos elencados naquele instrumento jurídico. Se o leitor estiver atento, notará que questões como "raça", "cor", "sexo", "etnia", "língua" e "religião", dentre outras tantas, talvez servissem como motivos que poderiam tornar uma pessoa inelegível para o gozo de diversos direitos que são considerados fundamentais para a vida e dignidade humana. Tais características constituem marcadores culturais (GRANT, 1983) e perfazem a identidade dos sujeitos e dos grupos humanos habitantes em todo o planeta. No espectro das diferenças e diante de perspectivas culturais e históricas de nuances distintas ao redor do mundo, o que é singular ou foge à pode ser expelido e ter seus direitos fundamentais negados. 
Servindo-se dos conceitos trabalhados por Ferdinand Saussure e Jacques Derrida, contemplamos aqui a ideia na qual a diferença é um elemento fundante da identidade, e não a sua opositora. Nesse sentido, entendemos a diferença como aquilo que é diferente em si, e não comparado aos demais. Tratamos assim daquilo que é único em sua excentricidade, e não de grupos similares entre si, são conceitos não binários que fogem a padrões regulares e determinados por ordenações sociais.

Em tempos de globalização e informações voláteis, em que as fronteiras territoriais e culturais tornaram-se extremamente permeáveis a fatores externos, torna-se importante compreender que a diferença contribui para enriquecimento cultural de um povo. A diferença manifestada por aspectos culturais, sociais, históricos e que performa de maneira individual não coloca em patamares irregulares as necessidades de acesso aos direitos fundamentais, não devendo assim determinar se sujeitos devem ou não ter acesso a tais direitos. Antes, podem ajudar a fundamentar as concepções de mundo de cada pessoa, contribuindo para uma vida plena (ONU, 2011).

\section{A SEMIOLOGIA DE SAUSSURE COMO PONTO DE PARTIDA}

A diferença será o principal conceito derridiano a ser abordado neste estudo, tendo como ponto de partida questionamentos sobre como Derrida o desenvolveu. Recorrendo aos conceitos desenvolvidos no campo da semiologia pelo linguista suíço Ferdinand de Saussure, Derrida (1991), pesquisou e desenvolveu conceitos de linguística geral, mas morreu antes de sistematizar suas ideias. A obra "Curso de Linguística Geral" só foi disponibilizada anos após sua morte, graças ao envolvimento de seus alunos, os quais compilaram suas anotações a respeito dos ensinos de Saussure. Nesta obra, Saussure (2006) mobiliza os conceitos de "signo", "significante" e "significado" aplicados à linguística, os quais Derrida transportará para o campo da filosofia, dando importante relevância à questão da diferença. À guisa de conceituações, Saussure (2006) define o signo linguístico como uma representação total de um objeto, a fim de torná-lo transmissível em forma de mensagem. Já o significante foi definido como a imagem acústica de um objeto, a qual se pode captar 
com algum dos órgãos de sentido. Por fim, o significado foi definido como sendo o conceito que o sujeito tem de determinado objeto.

Outra importante afirmação de Saussure (2006) é a de que o signo linguístico significa em razão de sua diferença em relação a outros signos. Isso se dá em razão de um sistema de valoração dos signos em face de outros signos, bem como a diferença existente entre um signo e outro. Assim, uma coisa só tem significado se for diferente de outra "coisa" (PINTO NETO, 2017b). Se não fosse assim, tudo uma mesma coisa, impossibilitando o discernimento e a formação de um sistema de signos compreensível. Portanto, é a diferença existente entre os signos linguísticos que possibilita a formação de uma comunidade de falantes de uma mesma língua (COBLEY; JANSZ, 2004).

\section{O USO DOS CONCEITOS DE SAUSSURE POR DERRIDA}

Quando mobiliza os conceitos saussurianos e os aplica à filosofia, Derrida promove um apagamento de algumas delimitações disciplinares. O filósofo Juvenal Savian Filho (TV CULT, 2014) afirma Derrida praticamente anula as fronteiras entre a literatura e a filosofia. Savian Filho também afirma que na obra de Derrida, as relações simbólicas, enquanto produção de sentido, funcionam como um grande texto, uma grande escritura. Por esse motivo, não faria sentido afastar o campo da literatura e o campo filosófico.

Tendo estabelecido certa similaridade entre esses campos, Derrida (1991) se apropria e amplia os conceitos de Saussure. O conceito mais importante a ser ampliado é o próprio conceito de signo. Derrida propõe o signo como sendo o sinal que ocupa o lugar de uma determinada coisa com a qual já se tenha vivenciado alguma experiência. Usa-se o signo quando a coisa mesma está ausente (DERRIDA, 1991).

Segundo a semiologia clássica, a substituição da coisa mesma pelo signo é simultaneamente secundária e provisória: secundária em relação a uma presença original e perdida de que o signo derivaria; provisória perante essa presença original e ausente em vista da qual o signo 
encontrar-se-ia num movimento de mediação (DERRIDA, 1991, p. 401).

Derrida (1991) também ampliou o alcance da diferença enquanto identificador dos signos linguístico. Isso o conduziu ao entendimento de que a identidade é estabelecida a partir da diferença. Entretanto, Derrida ultrapassa também esse conceito no campo da filosofia e afirma que diferença e identidade não são conceitos opostos entre si, mas interdependentes. Ele diz que um dos sentidos da palavra diferença remete à ideia de espaçamento ou de atraso que existe entre o signo e o significado. Devido à vasta possibilidades de significados possíveis para um signo, ele nunca representará perfeitamente o significado. Por outro lado, a diferença é também aquilo que impede a identidade perfeita entre dois objetos. Com base no "Curso de Linguística Geral" de Saussure (2006), Derrida afirma que a diferença permite que os dois entes sejam discerníveis e possibilite a alteridade. Resta, então, que existe uma diferença que não é um acidente da identidade; mas um constitutivo dela.

Pinto Neto (2017b) explica que essa diferença constitutiva precisava ser individualizada no discurso de Derrida. Por esse motivo, o filósofo provoca uma corruptela na grafia francesa da palavra "diferença" (diffèrence), alterando a letra "e" pela letra "a". De "diffèrence", a grafia da palavra passaria a "diffèrance". O jogo de palavras feito por Derrida só pode ser percebido na escrita e não na fala. Com isso, Derrida (1991) demonstra a multiplicidade de interpretações a que está aberta a escritura. E, como tudo no mundo estaria de alguma forma "escrito", segue-se que tudo é passível de transformação, mesmo em sua essência.

Derrida faz esse jogo de palavras por que em seu tempo diversos filósofos já abordavam a questão da diferença. Jean-François Lyotard, Michel Foucault e Giles Deleuze, por exemplo, já questionavam os ideais de identidade da sociedade europeia, os quais buscavam uma unidade às custas do sufocamento e eliminação das diferenças (PINTO NETO, 2017b). Pinto Neto (2017b) ainda afirma que a filosofia ocidental de então buscava reduzir o "outro" a uma repetição do "mesmo". Nogueira (2018) converge no mesmo sentido, considerando que a cultura ocidental, uma vez imposta como elemento organizador da sociedade, subalterniza, anula e invisibiliza 
outras formas de dar sentido às experiências de vida. $E$ é contra isso que se insurgiam aqueles filósofos da diferença (PINTO NETO, 2017b).

Tendo criado um neologismo para explicar o seu pensamento, Derrida (1991) prosseguiu no argumento a respeito da "diffèr ance", a partir dos estudos semiológicos de Ferdinand Saussure (2006), para quem - relembramos - os signos são valorados por sua demarcada diferença em relação a "outros signos". A partir dessa concepção, tem-se que as identidades são individualizadas pelas diferenças, corrupções e transgressões que envolvem essas mesmas identidades opondo-se a padrões ou normatizações sociais. Ainda assim, tais diferenças possuem uma origem fundante. É à essa origem das diferenças que Derrida chamou "diffèrance", com " $\underline{a}$ ". A diffèrance (e não a diffèrence), portanto, seria pré-individual; antecedendo até mesmo a identidade (PINTO NETO, 2017b).

\section{A GARANTIA DE DIREITOS NA DIFERENÇA}

Quando as sociedades elegem elementos culturais que integrarão a sua identidade de maneira padronizada e determinando o que deve ser considerado normal, deixam de fora uma série de outros elementos. Na verdade, os elementos culturais que foram excluídos da formação identitária, só o foram por não serem considerados tão bons quanto os que foram incluídos (SILVA, 2000).

Uma vez que um grupo seleciona seus marcadores identitários também se formam os grupos majoritários. Suas práticas e condutas são considerados como norma e a partir de então, estabelecem-se as relações de poder estruturadas que possibilitam ao grupo da norma hierarquizar e subordinar aqueles que se desviam da norma. Afinal, tudo aquilo que não atinge o padrão da norma estabelecida tende a ser valorado negativamente e hierarquizado como algo inferior (SILVA, 2000). Nesse sentido, há um grande risco de que esses grupos inferiorizados e "minoritários" passem a ter os seus direitos limitados e, até mesmo, cassados.

A experiência recente mostra que parece não serem raros os casos em que tais grupos são preteridos no acesso aos bens materiais e culturais. Alijados do processo 
de formação de leis por falta de representação política, por motivos históricos ou vulnerabilidade social, as "minorias" podem ver cassados os seus direitos à expressão de opinião, de manutenção da língua tradicional, de liberdade de crença e religião e, às vezes, até mesmo o direito à vida. É primordial que os movimentos sociais continuem pautando-se em fundamentos como os da filosofia da a diferençã e lutando pela busca por reconhecimento e por direitos que deveriam ser assegurados, apesar das aceitações de diferenças individuais ou de grupo (NOGUEIRA, 2018).

\section{CONSIDERAÇÕES FINAIS}

As contribuições de Ferdinand de Saussure no campo da semiologia foram essenciais para demonstrar que os signos linguísticos precisam ser diferentes entre si para que possam ser identificáveis e sistematizados. Por isso, ao se apropriar desse conceito, Derrida afirma que 0 ato da escrita possibilita o surgimento da diferença e que, na verdade, tanto a identidade quanto a diferença são fundadas por uma "diffèrance" que são pré-individuais. A compreensão de tais conceitos e sua explanação diante da defesa dos direitos fundamentais nos leva a uma melhor compreensão acerca da restrição de acesso existente de determinados grupos sociais a tais direitos.

A globalização e modernidade, ao trazerem consigo a ideia de liberdade e emancipação do indivíduo permitiram a complexificação dos conceitos de sujeito, igualdade, sociedade e cultura. Não se justifica, portanto, a uniformização das visões de mundo e o estabelecimento de um conceito único de verdade, visto que sufocam e impedem o aparecimento da diferença e a defesa das identidades. $\mathrm{E}$, independentemente de qualquer que seja o rastro de diferença sustentado pelos grupos humanos ou mesmo pelos sujeitos em suas singularidades, do diferente em si mesmo ou em relação ao outro, todos eles continuam sendo sujeitos de direitos, devendo ser respeitados em razão de sua dignidade inerente e de sua humanidade. 


\section{REFERÊNCIAS}

BREGANTIN, Paulo. Conversando sobre signo, significado e significante. 23 fev. 2015. Disponível em: <https://www.youtube.com/watch?v=n6JnwM0FXvQ>. Acesso em: 02 dez. 2018.

COBLEY, Paul; JANSZ, Litza. Semiótica para principiantes. Buenos Aires: Longseller, 2004, 160p.

DERRIDA, Jacques. A Diferença. In.: Margens da Filosofia. Campinas: Papirus, 1991, pp. $33-64$.

GRANT, Nigel. Multicultural education in Scotland. Comparative Education, v. 19, n. 2, 1983, pp. 133-153. Disponível em: <www.jstor.org/stable/3098827>. Acesso em: 31 jul. 2018.

KANT, Immanuel. Fundamentação da metafísica dos costumes. Tradução de Paulo Quintela. Lisboa: Edições 70, 2007.

LEOPOLDO E SILVA, Franklin. Deleuze: filosofia da diferença. Canal Casa do Saber. 28 fev. 2017. 07min46seg. Disponível em: <https://www.youtube.com/watch?v=6HerOPEsMao>. Acesso em: 15 nov. 2018.

NOGUEIRA, Paulo Henrique de Queiroz. Filosofia da Diferença. Programa de PósGraduação em Educação em Educação. 27 set. 2018. Notas de Aula. Faculdade de Educação da Universidade Federal de Minas Gerais.

ONU. Declaração Universal dos Direitos Humanos. Jan. 2009. Disponível em: <https://nacoesunidas.org/wp-content/uploads/2018/10/DUDH.pdf>. Acesso em: 02 dez. 2018.

PINTO NETO, Moysés. A escritura e a diferença I: bataille. Aula 08. Filosofia em Transe. 10 maio 2017a. Disponível em: $<$ https://www.youtube.com/watch?v=a5tDFcJp-MQ>. Acesso em: 01 dez. 2018. 
. Da Gramatologia, VI: O Ser Escrito (A Dyferença). Aula 18. Filosofia em Transe. 09 ago 2017b. Disponível em: <https://www.youtube.com/watch?v=hewJvNQ5T30\&list=PLRrHPCSYEQgizOUjtM3n YMj2mP3jKDKTT\&index=18>. Acesso em: 01 dez. 2018.

SANTOS, José Trindade. Da natureza: Parmênides. Brasília: Thesaurus, 2000.

SAUSSURE, Ferdinand de. Curso de linguística geral. São Paulo: Cultrix, 2006.

SILVA, Tomaz Tadeu da. A produção social da identidade e da diferença. In: Identidade e diferença: a perspectiva dos estudos culturais. 2. ed. Petrópolis: Vozes, 2000, p.73-102.

TV CULT investiga Jacques Derrida. TV Revista Cult. 08 out. 2014. Disponível em: $<h t t p s: / / w w w . y o u t u b e . c o m / w a t c h ? v=J s t T X J M b b-0>$. Acesso em 01 dez. 2018.

UNIVESP TV. Ferndinand de Saussure. Univesp TV. 31 mar. 2015. Disponível em: $<$ https://www.youtube.com/watch?v=JCZHz9n8JBU>. Acesso em: 01 dez. 2018.

Enviado: Novembro, 2019.

Aprovado: Dezembro, 2020. 